\title{
Education interventions for health professionals on falls prevention in health care settings: a 10-year scoping review
}

\author{
L. Shaw ${ }^{1,2^{*}}$ (D) D. Kiegaldie 3,4 and M. K. Farlie ${ }^{5}$ (D)
}

\begin{abstract}
Background: Falls in hospitals are a major risk to patient safety. Health professional education has the potential to be an important aspect of falls prevention interventions. This scoping review was designed to investigate the extent of falls prevention education interventions available for health professionals, and to determine the quality of reporting.

Method: A five stage scoping review process was followed based on Arksey and O'Malley's framework and refined by the Joanna Briggs Institute Methodology for JBI Scoping Reviews. Five online databases identified papers published from January 2008 until May 2019. Papers were independently screened by two reviewers, and data extracted and analysed using a quality reporting framework.

Results: Thirty-nine publications were included. Interventions included formal methods of educational delivery (for example, didactic lectures, video presentations), interactive learning activities, experiential learning, supported learning such as coaching, and written learning material. Few studies employed comprehensive education design principles. None used a reporting framework to plan, evaluate, and document the outcomes of educational interventions.

Conclusions: Although health professional education is recognised as important for falls prevention, no uniform education design principles have been utilised in research published to date, despite commonly reported program objectives. Standardised reporting of education programs has the potential to improve the quality of clinical practice and allow studies to be compared and evaluated for effectiveness across healthcare settings.
\end{abstract}

Keywords: Falls, Hospital, Health professional education, Prevention

\section{Background}

Falls are one of the most serious safety problems in healthcare facilities worldwide, and are associated with marked morbidity, mortality, increased length of stay and re-admissions [1-5]. Falls can also incur substantial costs to hospitals and healthcare providers, insurers and individuals [6-11]. Despite extensive research on interventions designed to reduce the incidence of falls in hospitals, the

\footnotetext{
* Correspondence: Louise.shaw@holmesglen.edu.au

${ }^{1}$ Faculty of Health Science, Youth and Community Studies, Holmesglen Institute, 488 South Road, Moorabbin, VIC 3189, Australia

${ }^{2}$ School of Allied Health, Human Services and Sport, La Trobe University, Bundoora, Victoria 3086, Australia

Full list of author information is available at the end of the article
}

quality of evidence is comparatively low, and the effects on falls risk in hospitals remains unclear $[12,13]$.

Education has been employed as a single intervention or as part of a multifactorial intervention in many falls prevention programs [12]. Much of the literature in this area has focussed on patient education in hospitals [3, 13-15], or elderly adults residing in the community or residential aged care [16-18]. Educating healthcare professionals about how to prevent falls has been recognised as a priority to improve patient safety in hospitals and residential care $[9,10]$. There remains a need for targeted examination of the impact of education to health professionals in prevention of falls, using behavioural

(c) The Author(s). 2020 Open Access This article is licensed under a Creative Commons Attribution 4.0 International License, which permits use, sharing, adaptation, distribution and reproduction in any medium or format, as long as you give appropriate credit to the original author(s) and the source, provide a link to the Creative Commons licence, and indicate if changes were made. The images or other third party material in this article are included in the article's Creative Commons licence, unless indicated otherwise in a credit line to the material. If material is not included in the article's Creative Commons licence and your intended use is not permitted by statutory regulation or exceeds the permitted use, you will need to obtain permission directly from the copyright holder. To view a copy of this licence, visit http://creativecommons.org/licenses/by/4.0/ The Creative Commons Public Domain Dedication waiver (http://creativecommons.org/publicdomain/zero/1.0/) applies to the data made available in this article, unless otherwise stated in a credit line to the data. 
change models or theoretical frameworks and principles of good education design [19-21].

A recent Cochrane review [12] on interventions for preventing falls in older people in residential aged care and hospitals, evaluated three studies that reported the outcomes of staff training programs. It limited the assessment to reduction in falls rates, and did not report educational methods or educational outcomes [12]. For health professionals to develop the necessary knowledge, skills and attitudes required to deliver evidence-based care in the prevention of falls, there is a need to understand the best ways to structure and deliver staff falls education [22]. The details reported in studies of health professional education trials is therefore important, yet the quality of reporting has been inconsistent and lacked detailed description [23-27].

For clinical research trials, a number of reporting guidelines have been developed to support the completeness of reporting [24]. These include the Consolidated Standards of Reporting Trials (CONSORT) for randomised trials [28-31], and the Preferred Reporting Items for Systematic Review and Meta-Analyses statement (PRISMA) [32-34]. The PRISMA checklist was further developed for the reporting of scoping reviews, (PRIS MA-ScR), to evaluate key items to be reported in scoping reviews. However, few education studies report whether conceptual frameworks guided development and implementation [20,35]. Previous systematic reviews investigating the quality of reporting in medical and health professions education have found informative educational elements are sometimes missing, such as context, educational design, reporting of education outcomes, and reporting of limitations [23, 25-27]. Inadequate reporting of the key elements of education interventions could compromise the ability to replicate and apply the findings [24]. Falls prevention education programs for clinicians that do not employ a theoretical framework in the design process, administration protocols, and procedures of the intervention, might lack scientific rigour [20, 21]. This could compromise the effectiveness of the intervention and its application in clinical practice [20].

Complete reporting of education design can benefit from the employment of a learning model such as Biggs' 3 P model [36], which offers insights into the nature of learning. It describes teaching context, student approaches to learning and the outcomes of learning as a system [36]. Biggs' integrated system comprises three components: Presage, Process and Product. Presage factors occur prior to learning and relate to the student (clinicians in this case) and teaching context [36]. Process factors are the processes that learners use to achieve tasks [36]. The Product phase is related to learning outcomes, with deep learning approaches expected to produce higher quality learning outcomes [36]. Kiegaldie (2015) suggested an extension to Biggs' model, known as the 4Ps approach to education design, with the additional ' $\mathrm{P}$ ' for Planning [35]. The inclusion of Planning emphasises the essential requirement for careful preparation and planning of education interventions. Presage and Planning go 'hand in hand', with Presage used to identify the issues/items, and Planning seen as the action plan to define what is needed to make the Presage happen [35]. The 4Ps approach is an iterative process, though equal attention is needed on every component [35]. Kiegaldie and Farlie (2019) proposed a quality tool for the design of education interventions [37] based on the extended 4Ps model. The conceptualisation of the 4Ps model as a checklist can assist evaluation of both education program quality and completeness of intervention reporting [37].

Given the limited reporting of a standard approach to health professional education on falls prevention, a scoping review was conducted to determine the nature of reported education programs. This scoping review aims to (i) investigate the extent of reporting of falls prevention education interventions for health professionals in a healthcare setting, (ii) appraise the quality of reporting of falls prevention education interventions using the 4Ps model of education design.

\section{Methods}

We utilised the Arksey and O'Malley methodological framework [38] for scoping reviews, which was refined by the Joanna Briggs Institute [39]. The protocol was drafted using the PRISMA-ScR checklist [40], which was revised by the research team (LS, MF, DK). This checklist has five sections: (a) identifying the research question, (b) identifying relevant studies, (c) identifying the study selection criteria, (d) charting the data and (e) reporting the results. The first four stages are methodological and will be reported in this section, whereas the fifth stage will be reported in the results section of this review.

\section{a) Identifying the research question}

The initial research question developed was, (i) What is the extent of education interventions delivered to health professionals (all those involved in caring for the individual including medical practitioners, nurses, allied health professionals and care facility staff), as a single intervention or as part of a multi-faceted intervention, that have been reported in the falls prevention literature? A secondary question was added to further focus the review, (ii) What is the quality of reporting of education interventions delivered to health professionals in the falls 
prevention literature? The authorship team consisted of researchers with clinical and educational expertise.

b) Identifying relevant studies

\section{Eligibility criteria}

The population of interest was health professionals who had received education related to falls prevention. The concept of interest was staff education on falls prevention, and the context of interest was any hospital or healthcare setting. Healthcare settings were defined as acute or sub-acute hospitals, residential aged care facilities, rehabilitation facilities, or long-term care facilities. Falls prevention education interventions to health professionals in the community were excluded. To be included, articles needed to be peer-reviewed and in the English language. Included articles needed to describe primary research of any design (quantitative, qualitative and mixed methods), such as a cluster randomised controlled trial, quality improvement project, prospective cohort studies, pre-post and repeated measure designs, and quasi experimental studies. They needed to investigate falls prevention interventions including a health professions education component, as either a single or part of a multifactorial set of interventions. Our intent was to review interventions from countries with similar pedagogical approaches (i.e. Australia, New Zealand, Canada, the United States of America, or the United Kingdom), with student-centred classes and active participation in the learning and teaching process [41]. The articles had to be accessible as full text, and published between January 2008 and May 2019. Exclusions were websites, handouts or other types of passive educational materials, book chapters and literature reviews.

\section{Search strategy}

A three-step search strategy was developed by the study group in collaboration with an academic librarian. The librarian executed the searches on behalf of the study group:

(i) Initial search of PubMed and Cumulative Index to Nursing and Allied Health Literature (CINAHL), to identify relevant studies to assist with search term development, based on the research questions and purpose of the study. The librarian helped guide a rigorous analysis process to identify the best search terms and strategy related to education of health professionals on falls prevention in institutional settings. The process was iterative, to ensure all relevant search terms were captured.

(ii) Analysis of words in the title and abstract of the initial retrieved papers and indexing terms used to classify the articles. (iii) Comprehensive search across PubMed, CINAHL, CENTRAL, PsycINFO and ERIC from January 2008 to May 2019, to ensure programs that were contemporary in terms of education design and falls prevention content. The reference lists of all identified studies were searched for additional studies meeting the inclusion criteria. We retrieved all supplementary files that were referred to in the included papers and any papers that were referred to in a particular study that were part of the research project.

Additional file 1 shows the complete search strategy executed in PubMed.

c) Study selection criteria

All studies identified from the search strategy were uploaded to Covidence [42]. Two reviewers (LS, MF) independently screened all titles and abstracts of retrieved papers. The same reviewers independently screened full texts to identify studies meeting the review criteria. Conflicts at each stage were resolved by discussion to consensus. If a consensus could not be reached, the third study group member (DK) was consulted. In all cases consensus was reached.

\section{d) Charting the data}

Data from eligible studies were charted independently by two researchers using a data extraction spreadsheet based on the 4Ps education design model (see Additional file 2) [37], which was developed as part of the study protocol. The tool captured the relevant information on key study characteristics, as well as Presage, Planning, Process and Product. The data extraction form was trialled by two reviewers (LS, MF) on three studies in duplicate to ensure that all relevant results were able to be captured. After which the same two reviewers independently charted the data for all included studies, and then compared and merged the data into a final dataset. Conflicts at the data merging stage were resolved by discussion to consensus. If a consensus could not be reached, the third study group member (DK) was consulted. In all instances consensus was reached.

\section{Results}

A summary of the key features of included studies are presented in Additional files 3, 4, 5, 6, 7. A total of 3015 records were retrieved from the 5 databases, following removal of duplicates. The results of the search strategy were charted using a PRISMA flow diagram (Fig. 1). On review of titles and abstracts 2833 records were identified as not meeting the inclusion criteria. Of those remaining, 182 full text articles were read and 143 were 


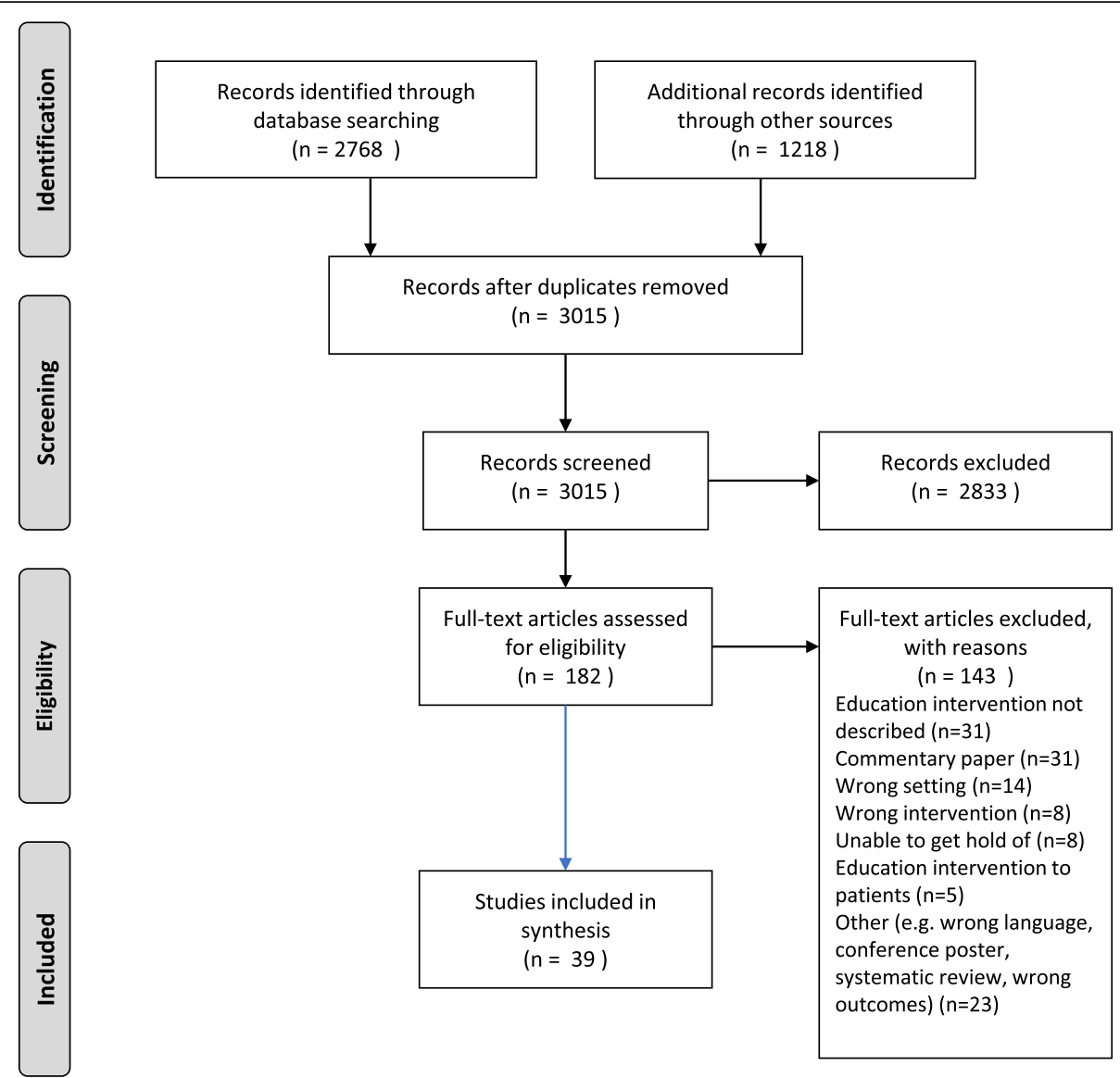

Fig. 1 Prisma Diagram of Scoping Review results for education to health professionals

excluded. The most common reasons for exclusion were education intervention not described $(n=39)$, no education intervention reported $(\mathrm{n}=31)$, commentary papers ( $\mathrm{n}=14$ ), and wrong study setting (not healthcare or hospital) $(\mathrm{n}=14)$. In summary, 39 articles were retained for this review.

\section{Study characteristics}

Additional file 3 outlines the study characteristics including the authors, year published, study design and country in which the study was conducted. The majority of the studies were from the USA $(\mathrm{n}=24)$, followed by Australia $(\mathrm{n}=8)$, Canada $(\mathrm{n}=3)$, Germany $(\mathrm{n}=2)$, and the United Kingdom $(\mathrm{n}=2)$.

\section{Types of study}

Where study design was explicitly reported, seven reported the design as a randomised controlled trial [4348]. Ten studies reported their design to be a pre-post study [49-58], one of these was reported as quasiexperimental [56], and six were cohort studies [51-55, 58]. One study was described as a quasi-experimental, pre-test/ post-test, pilot cohort [59]. Ten papers reported that their project was a quality improvement or implementation project, often advising that it was evidence based [46, 60-68]. Other study design descriptions included a multi-strategy interdisciplinary program implementation [69], education intervention [70], translational research intervention [71], or team training in a simulation environment [72].

\section{Presage and planning elements}

These elements are outlined in Additional file 4, which include the learning environment, methods of recruitment for the teachers, details of teachers' experience in education and falls prevention, and whether an evaluation was planned.

\section{Rationale for the use of education as an intervention}

For the majority of studies, the rationale for conducting education programs was related to the high rates of falls in hospitals and residential aged care, particularly for those over 65 years of age. Many studies described the consequences associated with falls, including high morbidity and mortality, and associated high economic costs. Researchers noted a lack of healthcare professional 
knowledge, awareness and skills for implementing fall prevention strategies. Studies reported a need for educationally sound and evidence-based programs that engaged multiple professions in interactive learning and clinically relevant problem solving to achieve high quality patient-centred care.

\section{Purpose of education interventions}

The purpose of education interventions was primarily described as increasing health professionals' knowledge, attitudes, skills and behaviour related to falls prevention, and determine whether health professions training had an effect on falls and injury rates. Some studies also reported aiming to improve interprofessional collaboration, communication and teamwork in managing falls. Most studies highlighted the importance of promoting adherence to current best practice falls prevention strategies. They also noted the value of ensuring that the safety education curriculum developed was evidence based.

\section{Study location}

Over two-thirds $(n=23)$ of the studies were conducted in a hospital. Nine were in residential aged care facilities, and three studies were conducted in a combined setting. The majority of studies were conducted 'in house' though the actual learning environment was not stated. A small number were conducted on wards, in classrooms, or in simulation centres.

\section{Resources}

Table 1 outlines the reported resources used to deliver the education. Most studies $(n=36)$ outlined the resources required to deliver the education program. In studies where this was not explicitly described, 'didactic learning materials' or 'practical workshop resources' were reported [44, 45, 69]. Some identified various support resources, brochures, or handouts, summarising the session and key learning points. One study described supplying a pack incorporating information from international best practice guidelines [58]. Another sent a support package to participants before the education intervention that included a copy of the presentation slides, reference to further readings, and a DVD of the assessment procedures to be covered [47]. One study provided a fall bundle toolkit that included a patient communication board, patient and family teaching materials, and related forms [78]. Of those studies that employed video, one video was a demonstration of an intervention [71], another study used video conferencing facilities to deliver falls prevention education to clinicians [75].

A range of facilities across the studies were used to deliver the training. These included seminar rooms, tutorial rooms, and training centres.

\section{Who taught the education program?}

The education programs were taught by a variety of educators, although it was not always clear who delivered the intervention. Around one-quarter of studies utilised nursing staff, who often had some expertise in falls prevention $[46,49,56,58-60,70,71,77,78,80]$. Other studies employed an interprofessional team, who were usually nominated based on their knowledge of falls prevention, commitment to patient safety or clinical skills $[53,55,61,63,65,75,79,81,82]$. One study reported employing a local expert in the field who had previously published in the area of falls prevention [47]. Four studies reported using trained interventionists to deliver the education, including change agents and falls 'champions' $[44,45,71,79]$. Research team members (including project representatives) were the educators in around onequarter $[43,46,48,51,52,54,64,68,69,76]$. Geriatrician clinical educators were the educators in two studies $[67,73]$, and where the study was carried out in a simulation centre, the simulation centre staff were the

Table 1 Resources used to deliver the education

\begin{tabular}{lll}
\hline Resources & No. of papers & Paper ID \\
\hline Didactic learning materials/ workshop resources & 3 & {$[44,45,69]$} \\
Support resources, brochures, or handouts & 10 & {$[44-46,48,53,67,70,71,73,74]$} \\
Resources required to deliver in-house education/ team presentations & 3 & {$[46,69,71]$} \\
Videos (support written material/ case studies/ clinical scenarios) & 9 & {$[47,51,63,71,73-77]$} \\
Presentation slides and visual aids & 13 & {$[43,46-49,57,59,64,66,77-80]$} \\
Online education modules & 6 & {$[44,45,62,68,74,80]$} \\
Role playing or case studies & 9 & {$[44,45,51,59,67,69,73,80,81]$} \\
Simulation & 2 & {$[60,72]$} \\
Knowledge surveys & 4 & {$[52-54,72]$} \\
Evaluation and feedback surveys & 2 & {$[57,81]$} \\
\hline
\end{tabular}


educators [60, 72]. Two studies involved self-directed learning $[50,74]$ and one study did not state who the educator was [62].

\section{Who were the learners?}

Uni-professional education programs were usually delivered to nursing staff, though three studies delivered education to medical staff or medical students $[52,69,83]$. One study reported interprofessional education to nursing and allied health staff, while junior doctors attended a separate session with greater emphasis on diagnosis and treatment of underlying conditions, run by a senior geriatrician [59]. Some studies stated that education was to all employees, or care facility staff but did not state whether they were clinical or non-clinical. Many studies reported educating all clinical staff involved in the care of the patient, including (but not limited to) nurses, physicians, social workers, physiotherapists, occupational therapists, speech therapists, pharmacists, dietitians, and healthcare aides. Five studies reported inclusion of non-professional clinical and support staff in their program delivery, including, for example, environmental services, maintenance, housekeepers, clerical staff, students, porters and laboratory and diagnostic technicians [44-46, 53, 74].

\section{How many learners were educated?}

Table 2 states how many learners were included in the education intervention. Eleven studies did not state how many learners were educated or it was unclear $[48,58$, $61,62,66,67,69,71,74,75,78]$. One study only reported the percentage of staff trained [49]. Another reported educating 'change agents' from 256 nursing homes but not the final number educated [71]. For some studies, there appeared to be a gradual attrition rate from the start of the study, to the completion of the educational content and subsequent completion of post study surveys.

\section{Process elements}

Additional file 5 describes the Process elements of educational interventions. Twenty-one studies reported that teachers were trained in how to deliver the program. Twenty-six studies reported that there were predetermined learning objectives. Of these, fourteen

Table 2 Number of learners in the education intervention

\begin{tabular}{lll}
\hline Number of learners & $\begin{array}{l}\text { No. of } \\
\text { papers }\end{array}$ & Paper ID \\
\hline $0-10$ & 2 & {$[51,57]$} \\
$10-50$ & 7 & {$[52,54,60,70,72,77,81]$} \\
$51-100$ & 11 & {$[50,53,55,56,59,63-65,68,79,83]$} \\
$100-200$ & 3 & {$[46,47,80]$} \\
$>200(300,471,658)$ & 3 & {$[44,45,76]$} \\
\hline
\end{tabular}

studies reported their objectives in behavioural terms. Eleven studies explicitly reported recognising learners' prior knowledge and a further eight studies appeared to informally recognise prior knowledge. Twenty-five studies reported some recognition of learners' prior experience. Three studies did not state the learning and teaching methods employed and three studies had no apparent alignment between the learning and teaching methods and their learning objectives.

\section{Teaching and learning process}

A range of teaching and learning activities were conducted across the studies and these are detailed in Additional file 6. The approaches employed for educating staff about falls prevention mainly focused on three

Table 3 Categories of teaching and learning approaches

\begin{tabular}{|c|c|}
\hline Teaching/ learning category & Sub categories \\
\hline \multirow[t]{5}{*}{ Methods of delivery } & Didactic lectures/ formal delivery \\
\hline & $\begin{array}{l}\text { Other oral presentation e.g. in- } \\
\text { service training }\end{array}$ \\
\hline & E-learning/ online \\
\hline & Self-directed learning \\
\hline & Video presentation/ demonstration \\
\hline \multirow[t]{9}{*}{$\begin{array}{l}\text { Interactive learning activities/ } \\
\text { experiential learning }\end{array}$} & $\begin{array}{l}\text { Group -based learning activities } \\
\text { (e.g. team presentations, problem } \\
\text { solving, brainstorming) }\end{array}$ \\
\hline & Debriefing sessions/ reflective dialogue \\
\hline & Station-based activities \\
\hline & $\begin{array}{l}\text { Case studies/ clinical scenarios } \\
\text { (paper-based) }\end{array}$ \\
\hline & Case studies/ clinical scenarios (video) \\
\hline & Role play \\
\hline & Simulation \\
\hline & Skills training \\
\hline & $\begin{array}{l}\text { Interactive learning activities } \\
\text { (details not described) }\end{array}$ \\
\hline \multirow[t]{5}{*}{ Supported learning } & $\begin{array}{l}\text { Individual mentoring/ coaching } \\
\text { or personal feedback }\end{array}$ \\
\hline & Bedside coaching \\
\hline & $\begin{array}{l}\text { Peer to peer discussion and } \\
\text { feedback/ staff huddles }\end{array}$ \\
\hline & Staff meetings \\
\hline & Team coaching \\
\hline \multirow[t]{4}{*}{ Written learning material } & Handouts \\
\hline & Resource folders \\
\hline & Falls assessment tool \\
\hline & Poster \\
\hline \multirow[t]{2}{*}{ Assessments } & Practical assessment \\
\hline & Knowledge assessment \\
\hline Other & Teleconferences \\
\hline
\end{tabular}


larger categories: methods of delivery, interactive learning activities/ experiential learning, and supported learning. There were three other minor categories: written learning material, assessments and 'other' which included teleconferences. These categories are detailed in Table 3. Often studies engaged a number of approaches.

\section{Methods of delivery}

Didactic lectures and formal delivery of content was the most commonly reported method of education to health professionals and was employed as a method of teaching in over half $(n=22)$ of the studies. Other methods of delivery utilised included in-service training $(\mathrm{n}=8)$, online teaching $(\mathrm{n}=8)$, self-directed learning $(\mathrm{n}=8)$ or video presentations and demonstrations $(\mathrm{n}=8)$.

\section{Interactive learning activities/ experiential learning}

Many of the studies supported formal content delivery with interactive learning activities. Around half $(\mathrm{n}=19)$ utilised group based learning activities, which included team presentations, problem solving and brainstorming. For example, in one study, participants rotated through four group learning stations in sixty minutes and completed a number of group tasks. These included identifying falls risk factors by synthesising data from a history and physical examination in a written clinical case study, and observing and documenting abnormal physical findings on gait videos [73]. Another commonly employed experiential learning method utilised by seventeen of the studies, was debriefing and reflective dialogue. The trial by Bursiek et al. (2017), presented an interdisciplinary simulation training scenario on patient falls, which was followed by a debriefing session and engagement of participants in reflective dialogue [72]. Participants in another study discussed the falls that had occurred on the patient care unit during the month at a falls meeting. This meeting included a discussion, brainstorming and reflection session about interventions that might work for the particular situations being discussed [56]. Fifteen of the studies included specific skills practice sessions, for example screening for falls, assessing gait, balance, orthostatic and other medical conditions, and often these sessions included opportunities for feedback.

\section{Supported learning}

Methods of supported learning reported in the studies included individual mentoring, bedside coaching, personal feedback or team coaching. Peer to peer discussion and feedback was reported as part of the teaching and learning process in over one-quarter $(n=11)$. One study reported multiple points of contact for peer-to-peer education such as at staff meetings, during start of shift huddles, via online education, and at 'Practice Council' meetings, to increase the likelihood of infusion of the proposed changes into real practice [62]. Another nine studies reported utilising individual mentoring, coaching or personal feedback. For example, participants in one study received 2 days of interactive team training followed by 3 months of coaching learners to implement their projects and share their stories and solutions with other teams [46].

\section{Written learning material}

The category of written learning material included teaching related to a falls assessment tool $(n=6)$. One study involved presenting information about the falls risk assessment tool to nurses, followed by discussion about how the tool and suggested interventions could be implemented at each of the sites [64]. Handouts and resource folders were utilised by some studies and one reinforced the falls prevention message via a poster for each session, which was displayed on a fall wall on each nursing unit [56].

\section{Assessment of learning}

One study reported assessing clinicians' practical skills [69]. Six studies assessed participants' knowledge, such as Haralambous and colleagues who tested knowledge of falls prevention risk factors and prevention interventions [58].

\section{Product elements}

Additional file 7 describes the Product elements of educational design. Thirty-two studies evaluated clinical outcomes, and twenty-seven studies evaluated educational outcomes. Thirty studies assessed learners' achievements of the learning objectives of stated purpose of the education program and twenty-nine studies conducted an evaluation of the education program. Data reported to evaluate the educational interventions included: pre and post knowledge tests; use of validated scales such as the Environment Assessment Scale, Mayo High Performance Teamwork Scale, Perceived Quality of Care Scale, and Safety Organizing Scale; ongoing process evaluation; observation of falls prevention interventions implemented post-education; questionnaires targeting knowledge change and practice change; and analysis of focus groups. Where clinical data was used to evaluate the education interventions, this was usually fall rates per 1000 bed days.

\section{Quality of health professions education programs}

Using a checklist based on the expanded 4Ps model, a summary table of a number of quality metrics was created, including whether the resources required were outlined, teacher and learner characteristics and evaluation planning (Table 4). 
Table 4 Quality scores for health professional education programs

\begin{tabular}{|c|c|c|c|c|c|c|}
\hline Lead Author & Study location & Learning environment & $\begin{array}{l}\text { Resources } \\
\text { required } \\
\text { outlined }\end{array}$ & $\begin{array}{l}{ }^{\mathrm{a}} \text { Teacher } \\
\text { characteristics } \\
\text { (/ 4) }\end{array}$ & $\begin{array}{l}\text { bLearners } \\
\text { characteristics } \\
\text { (/ 3) }\end{array}$ & $\begin{array}{l}\text { cEvaluation } \\
\text { planned and } \\
\text { executed? } \\
(/ 2)\end{array}$ \\
\hline Atkinson (2014) [73] & Other (AGS Conference) & Other -workshop at conference & $\checkmark$ & 4 & 3 & 2 \\
\hline Becker (2011) [71] & LTC/RACF only & LCF & $\checkmark$ & 2 & 2 & - \\
\hline Brennan (2018) [70] & Hospital only & Blended learning & $\checkmark$ & 3 & 3 & 2 \\
\hline Bursiek (2017) [72] & Hospital only & Simulation centre & $\checkmark$ & 1 & 3 & 2 \\
\hline Cabilan (2014) [49] & Hospital only & $\begin{array}{l}\text { Ward or independent } \\
\text { learning package }\end{array}$ & $\checkmark$ & 2 & 3 & 1 \\
\hline Campbell (2016) [78] & Hospital only & Ward & $\checkmark$ & 3 & 2 & 2 \\
\hline Caton (2011) [69] & Hospital only & In-house education program & $\checkmark$ & 4 & 2 & 2 \\
\hline Colon-Emeric (2017) [44] & LTC/RACF only & Blended learning & $\checkmark$ & 3 & 3 & 2 \\
\hline Colon-Emeric (2013) [45] & LTC/RACF only & Blended learning & $\checkmark$ & 3 & 3 & 2 \\
\hline Dilley (2014) [76] & LTC/RACF and community & $\begin{array}{l}\text { Other -in-house education } \\
\text { program }\end{array}$ & $\checkmark$ & 4 & 3 & - \\
\hline Eckstrom (2016) [79] & LTC/RACF and Hospital & Workshop plus coaching & $\checkmark$ & 4 & 2 & 2 \\
\hline Godlock (2016) [60] & Hospital only & Simulation centre & $\checkmark$ & 3 & 3 & 2 \\
\hline Gray-Miceli (2016) [46] & Hospital only & In-house education program & $\checkmark$ & 3 & 3 & - \\
\hline Gygax Spicer (2017) [61] & Hospital only & Ward & $\checkmark$ & 4 & 2 & - \\
\hline Haralambous (2010) [58] & LTC/RACF only & In-house education program & $\checkmark$ & 2 & 2 & 1 \\
\hline Heck (2014) [62] & Hospital only & Blended learning & $\checkmark$ & 4 & 2 & - \\
\hline Hill (2015) [75] & Hospital only & In-house education program & $\checkmark$ & 2 & 1 & - \\
\hline Ireland (2010) [74] & Hospital only & Blended learning & $\checkmark$ & 2 & 2 & 2 \\
\hline Johnson (2015) [50] & Hospital only & Online e-learning & $\checkmark$ & 3 & 3 & 2 \\
\hline Karnes (2011) [51] & $\begin{array}{l}\text { Outpatient rehabilitation } \\
\text { in hospital }\end{array}$ & In-house education program & $\checkmark$ & 2 & 3 & 2 \\
\hline Kempegowda (2018) [52] & Hospital only & Interprofessional workshop & $\checkmark$ & 4 & 3 & 2 \\
\hline Kent (2018) [81] & Hospital only & Interprofessional workshop & $\checkmark$ & 2 & 3 & 2 \\
\hline Lasater (2016) [63] & Other & Classroom & $\checkmark$ & 4 & 3 & 2 \\
\hline Leverenz (2018) [57] & LTC/RACF only & In-house education program & $\checkmark$ & 3 & 3 & 2 \\
\hline Lopez-Jeng (2019) [53] & Hospital only & In-house education program & $\checkmark$ & 3 & 3 & 2 \\
\hline Lugo (2014) [54] & Hospital only & In-house education program & $\checkmark$ & 2 & 3 & 2 \\
\hline Maloney (2011) [47] & $\begin{array}{l}\text { Hospital, LTC/RACF } \\
\text { and Community }\end{array}$ & Blended learning & $\checkmark$ & 3 & 3 & 2 \\
\hline McCarty (2018) [64] & Hospital only & In-house education program & $\checkmark$ & 2 & 3 & 1 \\
\hline McConnell (2009) [80] & Hospital only & Blended learning & $\checkmark$ & 3 & 3 & 2 \\
\hline McKenzie (2017) [65] & LTC/ RACF and hospital & Classroom & - & 2 & 3 & 2 \\
\hline Melin (2018) [66] & Hospital only & Face to face or online learning & $\checkmark$ & 2 & 2 & 1 \\
\hline Meyer (2009) [48] & LTC/RACF only & In-house education program & $\checkmark$ & 4 & 2 & 1 \\
\hline Singh (2016) [67] & Hospital only & In-house education program & $\checkmark$ & 3 & 2 & 2 \\
\hline Spiva (2014) [77] & Hospital only & In-house education program & $\checkmark$ & 4 & 3 & 2 \\
\hline Szymaniak (2015) [68] & Hospital only & Blended learning & $\checkmark$ & 3 & 3 & 2 \\
\hline Teresi (2013) [43] & LTC/RACF only & In-house education program & $\checkmark$ & 2 & 3 & 2 \\
\hline Toye (2017) [59] & Hospital only & In-house education program & $\checkmark$ & 4 & 3 & 2 \\
\hline Wheeler (2018) [55] & LTC/RACF only & Other & - & 4 & 3 & 2 \\
\hline Williams (2011) [56] & Hospital & Ward & $\checkmark$ & 4 & 3 & 2 \\
\hline
\end{tabular}

${ }^{a}$ Teacher characteristics (4): Who taught the education program? How were the teachers identified/recruited? Were the teachers qualified and/or experienced in teaching? Were the teachers qualified and/or experienced in the topic of falls prevention (subject matter experts)?

bLearner characteristics (2): Who were the learners? What was the configuration of the audience? How many learners were educated?

'Evaluation planned (2): Was there an assessment of the learners' achievement of the learning objectives or stated purpose of the education program? Was an evaluation of the education program conducted? 


\section{Discussion}

This scoping review based on 39 studies published from January 2008 to May 2019, provides a comprehensive review of studies that have investigated education to health professionals on falls prevention in hospitals and healthcare settings. We identified a limited number of studies that primarily focussed on describing education interventions to health professionals on falls prevention, either as a single intervention or as part of a multifactorial organisational strategy. The overall finding was that the rigour of design and reporting of clinician educational interventions for falls prevention are often not comprehensive.

The evidence synthesis in this review was complex due to wide variation in the methods and quality of reporting, and extensive variability in educational approaches, rationale, purposes and methods of evaluation. Of the 182 full text articles that were screened to determine their suitability for this study, thirty-nine were rejected as the education intervention was not described. Previous reviews have likewise identified that education intervention reporting is inconsistent and often incomplete [23, 25-27, 84]. For example, studies evaluating education interventions related to cancer pain, found deficiencies in the extent and quality of reporting, with many studies lacking detailed descriptions of the format and content of their education programs $[85,86]$. A review of simulation research for health professions education also noted that studies often failed to describe the context of the research, instructional design and outcomes [23]. In the reviewed studies, deficiencies in reporting were common with authors providing few details about the content of their education programs, which made it difficult to categorise and interpret the findings. Clear and concise reporting of education interventions helps readers understand how the education was delivered in the research [84]. Poor and inconsistent reporting of education interventions makes it difficult to interpret results and replicate interventions [84]. Hence it is less likely the research will inform change that will positively influence target outcomes [84].

\section{Presage and planning elements}

None of the studies we evaluated used a quality framework to design their intervention, and few studies reported the different elements required for developing and reporting an education intervention. Inadequately describing the key elements of a research study means that others are unable to apply and replicate the methods [87]. For example, a core principle of education interventions is the educational dose intensity [88]. However, in the studies that we reviewed, the duration of the education interventions, the learning environment and other relevant information to characterise the dose was often difficult to find.

Use of the 4Ps framework [37], may assist a quality assurance process where all key elements are considered in the design and reporting of health professional education programs. This has been used successfully in other health professional contexts such as in interprofessional learning [89-91] and simulation-based education (SBE) [84]. In the SBE context, Cheng and colleagues argue for an improvement in the quality of reporting for SBE and have developed and published guidelines for healthcare simulation research inclusive of educational design features [84]. The use of standardised reporting of education design according to these types of frameworks will focus attention to the important elements for quality improvement into the future.

Process elements -content of the education interventions We found discrepancies in the content of education programs in studies with multiple teaching and learning strategies employed, which made the efficacy of each component difficult to determine [86]. Additionally, education interventions were poorly described, limiting the ability of the reader to fully understand the process, as well as making replication challenging. Formal delivery was the most common teaching strategy. Studies optimising health professions education in other diseases such as heart failure [92] and cancer [88] have demonstrated the importance of active learning for adult learners to improve their self-efficacy and level of knowledge of the disease. A scoping review that examined concussion education programs found that the education programs had limited use of interactive tools, delivered education at one time point only and lacked longterm assessment [93]. Our review revealed that whilst didactic lectures was the most common form of delivery, this was usually combined with other interactive learning activities, including skills training, or supported learning, with feedback or coaching. The time spent on education also varied greatly making it difficult to determine the most efficient and cost effective manner [86]. Many delivered education at one time point only, whilst others recognised the importance of follow up and reinforcement sessions via team meetings, teleconferences, peer to peer feedback or bedside coaching. More research is needed to determine the education program processes that could improve participants' long term knowledge, attitudes and behaviours after being exposed to a falls education program [93].

\section{Product -outcomes and evaluation}

Primarily, the outcomes were often measured in clinical terms, related to the number of falls, rather than behaviour change. The methods employed for outcome 
measurement also varied with quantitative instruments such as surveys, quizzes and questionnaires being the most common evaluation tools. The wide variety of approaches make it difficult to compare studies. Using robust and validated outcome measures will improve this field. Recommendations made on reporting outcome measures for cancer pain educational interventions, stated that all study designs should report on the prospectively selected primary outcome, and the tools and tests used to achieve this [88].

Evaluation of clinician training is often considered to be a low priority [94]. Application of the extended 4Ps model [37] to the studies in this review of education interventions in falls prevention, has provided stratified assessment of the use of education evaluation which highlights stronger study designs without unnecessarily discounting partially helpful information [95]. Evaluating the behavioural outcomes of education programs is important given that behaviour change is an important goal of the education. It is therefore recommended that the primary endpoints for research on health professional education programs in falls prevention should not only focus on falls and injury rates and costs. The clinical assumption of patient benefit as a reference standard of evidence should be rejected [95] and we call for researchers to also measure behavioural outcomes. Effective training measured in terms of behavioural change, such as the transfer of knowledge and skills gained from training into practice $[88,96]$, may potentially lead to a reduction in the rate of falls. The evaluation of education interventions using qualitative and quantitative measures could be incorporated into future falls prevention education programs for health professionals [95].

\section{Limitations}

Including the synthesis of qualitative and quantitative research in the same review [97], and balancing the breadth and depth of analysis [98], was challenging. The sources of evidence for this review are limited because we excluded articles that were not published in countries with similar pedagogical approaches, only reported on falls prevention to health professionals in hospitals or healthcare facilities, and excluded non-empirical studies. Reporting of training undertaken for the teachers or facilitators of the education interventions could be considered as an addition to the framework in future studies. The application of the extended 4Ps model as a quality assessment tool for evaluation of educational reporting was theoretically driven. The 4Ps model awaits further formal validation [37].

\section{Conclusions}

Our scoping review highlighted gaps in the planning, reporting and evaluation processes for health professional education in falls prevention. It also generated a recommendation to adopt a more comprehensive approach. We found a variety of methods for education of health professionals in falls prevention. Investigation and reporting of well-designed education programs for health professionals on falls prevention in institutional settings is needed to determine the effectiveness of this type of intervention for falls prevention. Use of a standardised reporting framework for education interventions in falls prevention research, such as the extended 4Ps model, has the potential to improve knowledge and prevent falls.

\section{Supplementary information}

Supplementary information accompanies this paper at https://doi.org/10. 1186/s12877-020-01819-x.

Additional file 1. Example search strategy PUBMED

Additional file 2. Modified 4Ps model of quality in education design

Additional file 3. Study characteristics

Additional file 4. Presage and planning elements of education interventions

Additional file 5. Process elements of education interventions

Additional file 6. Teaching and learning activities

Additional file 7. Product elements of education interventions

\section{Abbreviations}

JBI: Joanna Briggs Institute Methodology; CONSORT: Consolidated Standards of Reporting Trials; PRISMA: Preferred Reporting Items for Systematic Review and Meta-Analyses statement; PRISMA-ScR: Preferred Reporting Items for Systematic Review and Meta-Analyses statement for scoping reviews; Biggs' 3P model: Presage, Process and Product; Kiegaldie's 4Ps model: Presage, Process, Product and Planning; LS: Louise Shaw; MF: Melanie Farlie;

DK: Debra Kiegaldie; CINAHL: Cumulative Index to Nursing and Allied Health Literature; CENTRAL: The Cochrane Central Register of Controlled Trials; ERIC: Education Resources Information Center; SBE: Simulation Based Education

\section{Acknowledgements}

The authors thank Healthscope and Holmesglen Institute for their valuable support, particularly Yvonne Hamey, Holmesglen Institute librarian.

\section{Authors' contributions}

LS, MF and DK conceptualised the study. All authors were involved in the design and writing. LS and MF were responsible for searching, screening and selecting studies. LS was the main author. MF and DK were critical readers and revisers of the manuscript. The authors gave final approval to submit this paper.

\section{Funding}

The scoping review was conducted as part of an Australian National Health and Medical Research Council Project Grant (Morris et al., GNT1152853) in partnership with Healthscope, Holmesglen Institute and several Australian universities. The research was conducted independently from the funding body.

Availability of data and materials

The datasets used and/or analysed during the current study are available from the corresponding author on reasonable request.

Ethics approval and consent to participate Not applicable. 


\section{Consent for publication}

Not applicable.

\section{Competing interests}

The authors declare that they have no competing interests.

\section{Author details}

${ }^{1}$ Faculty of Health Science, Youth and Community Studies, Holmesglen Institute, 488 South Road, Moorabbin, VIC 3189, Australia. ${ }^{2}$ School of Allied Health, Human Services and Sport, La Trobe University, Bundoora, Victoria 3086, Australia. ${ }^{3}$ Faculty of Health Science, Youth and Community Studies and Healthscope Hospitals, Holmesglen Institute, 488 South Road, Moorabbin, VIC 3189, Australia. ${ }^{4}$ Eastern Clinical School, Faculty of Medicine, Nursing \& Health Sciences, Monash University, Melbourne, Australia. ${ }^{5}$ Department of Physiotherapy, School of Primary and Allied Health Care, Faculty of Medicine, Nursing and Health Sciences, Monash University, Moorooduc Highway, Frankston, VIC 3199, Australia.

Received: 3 June 2020 Accepted: 5 October 2020 Published online: 09 November 2020

\section{References}

1. Hill A-M, McPhail SM, Haines TP, Morris ME, Etherton-Beer C, Shorr R, et al. Falls after hospital discharge: a randomized clinical trial of individualized multi-modal falls prevention education. J Gerontol Ser A Biol Med Sci. 2019; 74(9):1511-7.

2. Haines TP, Bennell KL, Osborne RH, Hill KD. Effectiveness of targeted falls prevention programme in subacute hospital setting: randomised controlled trial. Br Med J. 2004;328(7441):676+.

3. Haines TP, Hill AM, Hill KD, McPhail S, Oliver D, Brauer S, et al. Patient education to prevent falls among older hospital inpatients: a randomized controlled trial. Arch Intern Med. 2011;171(6):516-24.

4. Healey F, Monro A, Cockram A, Adams V, Heseltine D. Using targeted risk factor reduction to prevent falls in older in-patients: a randomised control trial. Age Ageing. 2004;33(4):390-5.

5. Nyberg L, Gustafson Y. Using the downtown index to predict those prone to falls in stroke rehabilitation. Stroke. 1996;27(10):1821-4.

6. Burns ER, Stevens JA, Lee R. The direct costs of fatal and non-fatal falls among older adults — United States. J Safety Res. 2016;58:99-103.

7. Morello RT, Barker AL, Watts JJ, Haines T, Zavarsek SS, Hill KD, et al. The extra resource burden of in-hospital falls: a cost of falls study. Med J Aust. 2015; 203(9):367.

8. Florence CS, Bergen G, Atherly A, Burns E, Stevens J, Drake C. Medical costs of fatal and nonfatal falls in older adults. J Am Geriatr Soc. 2018;66(4):693-8.

9. Abraham SP. Psychiatric nursing directors' perceptions of the factors contributing to patient falls in psychiatric inpatient units: University of Phoenix; 2012. https://search.proquest.com/docview/1269150702?pqorigsite $=$ gscholar\&fromopenview $=$ true.

10. Hang J-A, Francis-Coad J, Burro B, Nobre D, Hill A-M. Assessing knowledge, motivation and perceptions about falls prevention among care staff in a residential aged care setting. Geriatr Nurs. 2016;37(6):464-9.

11. Büchele G, Becker C, Cameron ID, König H-H, Robinovitch S, Rapp K. Predictors of serious consequences of falls in residential aged care: analysis of more than 70,000 falls from residents of Bavarian nursing homes. J Am Med Dir Assoc. 2014;15(8):559-63.

12. Cameron ID, Dyer SM, Panagoda CE, Murray GR, Hill KD, Cumming RG, et al. Interventions for preventing falls in older people in care facilities and hospitals. Cochrane Database Syst Rev. 2018;9:CD005465.

13. Heng $H$, Jazayeri $D$, Shaw L, Kiegaldie D, Hill A-M, Morris ME. Hospital falls prevention with patient education: a scoping review. BMC Geriatr. 2020; 20(1):140.

14. Hill A, McPhail S, Hoffmann T, Hill K, Oliver D, Beer C, et al. A randomized trial comparing digital video disc with written delivery of falls prevention education for older patients in hospital. J Am Geriatr Soc. 2009;57(8):145863.

15. Lee D-CA, Pritchard E, McDermott F, Haines TP. Falls prevention education for older adults during and after hospitalization: a systematic review and meta-analysis. Health Educ J. 2014;73(5):530.

16. Abrahamson K, Davila H, Mueller C, Inui T, Arling G. Examining the lived experience of nursing home quality improvement: the case of a multifacility falls reduction project. J Gerontol Nurs. 2013;39(9):24-30 quiz 2-3.
17. Schoberer D, Eglseer D, Halfens RJG, Lohrmann C. Development and evaluation of brochures for fall prevention education created to empower nursing home residents and family members. Int J Older People Nurs. 2018; 13(2):e12187.

18. Taylor N. A patient education program supported by staff training can reduce the rate of falls for older patients during inpatient rehabilitation [synopsis]. Aust J Physiother. 2015;61(4):224.

19. Brandt B, Lutfiyya MN, King JA, Chioreso C. A scoping review of interprofessional collaborative practice and education using the lens of the triple aim. J Interprof Care. 2014;28(5):393-9.

20. Schepens SL. The effectiveness of tailoring falls prevention education for older adults. Detroit: Wayne State University; 2009. https://search.proquest. com/docview/305020189/fulltextPDF/14E1DEAEB5D24D4APQ/1?accountid= 132066.

21. Schepens SL, Panzer V, Goldberg A. Randomized controlled trial comparing tailoring methods of multimedia-based fall prevention education for community-dwelling older adults. Am J Occup Ther. 2011;65(6):702-9.

22. Hecht L, Buhse S, Meyer G. Effectiveness of training in evidence-based medicine skills for healthcare professionals: a systematic review. BMC Med Educ. 2016;16:103.

23. Cook DA, Hatala R, Brydges R, Zendejas B, Szostek JH, Wang AT, et al. Technology-enhanced simulation for health professions education: a systematic review and meta-analysis. Jama. 2011;306(9):978-88.

24. Cheng A, Eppich W, Grant V, Sherbino J, Zendejas B, Cook DA. Debriefing for technology-enhanced simulation: a systematic review and meta-analysis. Med Educ. 2014;48(7):657-66.

25. Cook DA, Beckman TJ, Bordage G. A systematic review of titles and abstracts of experimental studies in medical education: many informative elements missing. Med Educ. 2007;41(11):1074-81.

26. Cook DA, Beckman TJ, Bordage G. Quality of reporting of experimental studies in medical education: a systematic review. Med Educ. 2007;41(8): 737-45.

27. Cook DA, Levinson AJ, Garside S. Method and reporting quality in health professions education research: a systematic review. Med Educ. 2011;45(3): 227-38.

28. Moher D, Schulz KF, Altman DG, Group C. The CONSORT statement: revised recommendations for improving the quality of reports of parallel-group randomized trials. J Am Podiatr Med Assoc. 2001;91(8):437-42.

29. Moher D, Hopewell S, Schulz KF, Montori V, Gotzsche PC, Devereaux PJ, et al. CONSORT 2010 explanation and elaboration: updated guidelines for reporting parallel group randomised trials. J Clin Epidemiol. 2010;63(8):e1-37.

30. Moher D, Altman DG, Schulz KF, Elbourne DR. Opportunities and challenges for improving the quality of reporting clinical research: CONSORT and beyond. Can Med Assoc J. 2004;171(4):349-50.

31. Plint AC, Moher D, Morrison A, Schulz K, Altman DG, Hill C, et al. Does the CONSORT checklist improve the quality of reports of randomised controlled trials? A systematic review. Med J Aust. 2006;185(5):263-7.

32. Moher D, Shamseer L, Clarke M, Ghersi D, Liberati A, Petticrew M, et al. Preferred reporting items for systematic review and meta-analysis protocols (PRISMA-P) 2015 statement. Syst Rev. 2015;4:1.

33. Moher D, Liberati A, Tetzlaff J, Altman DG, Group P. Preferred reporting items for systematic reviews and meta-analyses: the PRISMA statement. J Clin Epidemiol. 2009;62(10):1006-12.

34. Liberati A, Altman DG, Tetzlaff J, Mulrow C, Gotzsche PC, loannidis JP, et al. The PRISMA statement for reporting systematic reviews and meta-analyses of studies that evaluate health care interventions: explanation and elaboration. J Clin Epidemiol. 2009;62(10):e1-34.

35. Kiegaldie D. Learning about delirium in a simulated clinical environment: an interprofessional learning intervention for final year medical and nursing students. Melbourne: Monash University; 2015. https://www.researchgate. net/profile/Debra_Kiegaldie/publication/332410998_Learning_about_ Delirium_in_a_Simulated_Clinical_Environment_An_Interprofessional_ Learning_Intervention_for_Final_Year_Medical_and_Nursing_Students/ links/5cc7b8e34585156cd7bbba54/Learning-about-Delirium-in-a-SimulatedClinical-Environment-An-Interprofessional-Learning-Intervention-for-FinalYear-Medical-and-Nursing-Students.pdf.

36. Biggs JB. From theory to practice: a cognitive systems approach. High Educ Res Dev. 1993;12(1):73-85.

37. Kiegaldie DJ, Farlie MK. Using education interventions in falls research: a framework for evidence-based education design. 2nd ed. Melbourne: Holmesglen Institute; 2019. 
38. Arksey H, O'Malley L. Scoping studies: towards a methodological framework. Int J Soc Res Methodol. 2005;8(1):19-32

39. Peters MD, Godfrey CM, Khalil H, Mclnerney P, Parker D, Soares CB. Guidance for conducting systematic scoping reviews. Int J Evid Based Healthc. 2015;13(3):141-6.

40. Tricco AC, Lillie E, Zarin W, O'Brien KK, Colquhoun H, Levac D, et al. PRISMA extension for scoping reviews (PRISMA-SCR): checklist and explanation. Ann Intern Med. 2018;169(7):467-73.

41. Iyer RB. Blending east and west for holistic education. Educ Res Rev. 2015; 10(3):244-8.

42. Cochrane Community. Covidence 2019 [Available from: https://community. cochrane.org/help/tools-and-software/covidence..

43. Teresi JA, Ramirez M, Remler D, Ellis J, Boratgis G, Silver S, et al. Comparative effectiveness of implementing evidence-based education and best practices in nursing homes: effects on falls, quality-of-life and societal costs. Int J Nurs Stud. 2013;50(4):448-63.

44. Colón-Emeric CS, Corazzini K, McConnell ES, Wei P, Toles M, Hall R, et al. Effect of promoting high-quality staff interactions on fall prevention in nursing homes: a cluster-randomized trial. JAMA Intern Med. 2017;177(11): 1634-41.

45. Colon-Emeric CS, McConnell E, Pinheiro SO, Corazzini K, Porter K, Earp KM, et al. CONNECT for better fall prevention in nursing homes: results from a pilot intervention study. J Am Geriatr Soc. 2013;61(12):2150-9.

46. Gray-Miceli D, Mazzia L, Crane G. Advanced practice nurse-led statewide collaborative to reduce falls in hospitals. J Nurs Care Qual. 2016;32(2):120-5.

47. Maloney S, Haas R, Keating JL, Molloy E, Jolly B, Sims J, et al. Effectiveness of web-based versus face-to-face delivery of education in prescription of fallsprevention exercise to health professionals: randomized trial. J Med Internet Res. 2011;13(4):e116.

48. Meyer G, Kopke S, Haastert B, Muhlhauser I. Comparison of a fall risk assessment tool with nurses' judgement alone: a cluster-randomised controlled trial. Age Ageing. 2009;38(4):417-23.

49. Cabilan CJ. Falls risk assessment and falls prevention strategies in private oncology and neurosurgical setting: a best practice implementation project. JBI Database System Rev Implement Rep. 2014;12(10):218-33.

50. Johnson M, Kelly L, Siric K, Tran DT, Overs B. Improving falls risk screening and prevention using an e-learning approach. J Nurs Manag. 2015;23(7): 910-9.

51. Karnes MJ. Improving fall risk factor identification and documentation of risk reduction strategies by rehabilitation therapists through continuing education: D'Youville College; 2011. https://search.proquest.com/ openview/1af19bclee9d658d50983c264c7eca0a/1?cbl=18750\&diss=y\&pqorigsite $=$ gscholar.

52. Kempegowda P, Chandan JS, Hutton R, Brown L, Madden W, Webb J, et al. Focused educational intervention improves but may not sustain knowledge regarding falls management. BMJ Open Qual. 2018;7(3):e000222.

53. Lopez-Jeng C, Eberth SD. Improving hospital safety culture for falls prevention through interdisciplinary health education. Health Promot Pract. 2019. https://doi.org/10.1177/1524839919840337.

54. Lugo I. Educating staff nurses on fall prevention strategies in hospice Austin patients: knowledge enhancement: Walden University; 2014. www.proquest. com/docview/1502869520?accountid=132066.

55. Wheeler E, Coogle CL, Fix RC, Owens MG, Waters LH. Physical and occupational therapy practice improvement following interprofessional evidence-based falls prevention training. J Allied Health. 2018;47(1):9-18

56. Williams B, Young S, Williams D, Schindel D. Effectiveness of a fall awareness and education program in acute care. J Nurses Staff Dev. 2011;27(3):143-7.

57. Leverenz MD, Lape J. Education on fall prevention to improve self-efficacy of nursing staff in long term care: a pilot study. Internet J Allied Health Sci Pract. 2018;16(3):1-10.

58. Haralambous B, Haines TP, Hill K, Moore K, Nitz J, Robinson A. A protocol for an individualised, facilitated and sustainable approach to implementing current evidence in preventing falls in residential aged care facilities. BMC Geriatr. 2010;10:8.

59. Toye C, Kitchen S, Hill A, Edwards D, Sin M, Maher S. Piloting staff education in Australia to reduce falls in older hospital patients experiencing delirium. Nurs Health Sci. 2017;19(1):51-8.

60. Godlock G, Christiansen M, Feider L. Implementation of an evidence-based patient safety team to prevent falls in inpatient medical units. Medsurg Nurs. 2016;25(1):17-23.
61. Gygax SJ. The got-a-minute campaign to reduce patient falls with injury in an acute care setting. Medsurg Nurs. 2017;26(5):313-26.

62. Heck J, Gebhart A, Gaehle KE. Accountability and teamwork: tools for a fallfree zone. Nurs Manage. 2014;46(1):40-5.

63. Lasater K, Cotrell V, McKenzie G, Simonson W, Morgove MW, Long EE, et al. Collaborative falls prevention: Interprofessional team formation, implementation, and evaluation. J Contin Educ Nurs. 2016;47(12):545-50.

64. McCarty CA, Woehrle TA, Waring SC, Taran AM, Kitch LA. Implementation of the MEDFRAT to promote quality care and decrease falls in community hospital emergency rooms. JEN: J Emerg Nurs. 2018;44(3):280-4.

65. McKenzie G, Lasater K, Delander GE, Neal MB, Morgove M, Eckstrom E. Falls prevention education: Interprofessional training to enhance collaborative practice. Gerontol Geriatr Educ. 2017;38(2):232-43.

66. Melin CM. Reducing falls in the inpatient hospital setting. Int J Evid Based Healthc. 2018;16(1):25-31.

67. Singh I, Okeke J. Reducing inpatient falls in a 100\% single room elderly care environment: evaluation of the impact of a systematic nurse training programme on falls risk assessment (FRA). BMJ Qual Improv Rep. 2016;5(1).

68. Szymaniak S. Accurate falls risk assessment and interventions for preventing falls in patients in the acute care setting within a private hospital in a large capital city: a best practice implementation project. JBI Database System Rev Implement Rep. 2015;13(9):386-406.

69. Caton C, Wiley MK, Zhao Y, Moran WP, Zapka J. Improving internal medicine residents' falls assessment and evaluation: an interdisciplinary, multistrategy program. J Am Geriatr Soc. 2011;59(10):1941-6.

70. Brennan D. Patient self-assessment for older adult fall prevention; 2018. https://scholarworks.waldenu.edu/cgi/viewcontent.cgi?article $=6276$ \&context=dissertations.

71. Becker C, Cameron ID, Klenk J, Lindemann U, Heinrich S, Konig HH, et al. Reduction of femoral fractures in long-term care facilities: the Bavarian fracture prevention study. PLoS One. 2011;6(8):e24311.

72. Bursiek AA, Hopkins MR, Breitkopf DM, Grubbs PL, Joswiak ME, Klipfel JM, et al. Use of high-Fidelity simulation to enhance interdisciplinary collaboration and reduce patient falls. J Patient Saf. 2017;16(3):245-50. https://doi.org/10.1097/PTS.0000000000000277.

73. Atkinson HH, Tan ZS, Brennan M, Granville L. A collaborative National Model to assess competencies for medical students, residents, and other healthcare practitioners in gait and falls risk evaluation. J Am Geriatr Soc. 2014;62(6):1155-60.

74. Ireland S, Lazar T, Mavrak C, Morgan B, Pizzacalla A, Reis C, et al. Designing a falls prevention strategy that works. J Nurs Care Qual. 2010;25(3):198-207.

75. Hill AM, McPhail SM, Waldron N, Etherton-Beer C, Ingram K, Flicker L, et al. Fall rates in hospital rehabilitation units after individualised patient and staff education programmes: a pragmatic, stepped-wedge, cluster-randomised controlled trial. Lancet (London, England). 2015;385(9987):2592-9.

76. Dilley LB, Gray SM, Zecevic A, Gaspard G, Symes B, Feldman F, et al. An educational video to promote multi-factorial approaches for fall and injury prevention in long-term care facilities. BMC Med Educ. 2014;14:102.

77. Spiva L, Robertson B, Delk ML, Patrick S, Kimrey MM, Green B, et al. Effectiveness of team training on fall prevention. J Nurs Care Qual. 2014; 29(2):164-73.

78. Campbell BD. Fall safety bundle; 2016. https://scholarworks.waldenu.edu/ cgi/viewcontent.cgi?article=3900\&context=dissertations.

79. Eckstrom E, Neal MB, Cotrell V, Casey CM, McKenzie G, Morgove MW, et al. An Interprofessional approach to reducing the risk of falls through enhanced collaborative practice. J Am Geriatr Soc. 2016;64(8):1701-7.

80. McConnell ES, Lekan D, Bunn M, Egerton E, Corazzini KN, Hendrix CD, et al. Teaching evidence-based nursing practice in geriatric care settings: the geriatric nursing innovations through education institute. J Gerontol Nurs. 2009;35(4):26-33 quiz 4-5.

81. Kent F, Courtney J, Thorpe J. Interprofessional education workshops in the workplace for pre-registration learners: aligning to national standards. Nurse Educ Today. 2018;62:58-61.

82. Hill A-M, McPhail SM, Waldron N, Etherton-Beer C, Ingram K, Flicker L, et al. Fall rates in hospital rehabilitation units after individualised patient and staff education programmes: a pragmatic, stepped-wedge, cluster-randomised controlled trial. Lancet (London, England). 2015;385North American Edition(9987):2592-9.

83. Atkinson HH, Lambros A, Davis BR, Lawlor JS, Lovato J, Sink KM, et al. Teaching medical student geriatrics competencies in 1 week: an efficient 
model to teach and document selected competencies using clinical and community resources. J Am Geriatr Soc. 2013;61(7):1182-7.

84. Cheng A, Kessler D, Mackinnon R, Chang TP, Nadkarni VM, Hunt EA, et al. Reporting guidelines for health care simulation research: extensions to the CONSORT and STROBE statements. Adv Simul (Lond). 2016;1:25.

85. Irajpour A, Norman I, Griffiths P. Interprofessional education to improve pain management. Br J Community Nurs. 2006;11(1):29-32.

86. MacLaren JE, Cohen LL. Teaching behavioral pain management to healthcare professionals: a systematic review of research in training programs. J Pain. 2005;6(8):481-92.

87. Begley CG, loannidis JP. Reproducibility in science: improving the standard for basic and preclinical research. Circ Res. 2015;116(1):116-26.

88. Stiles CR, Biondo PD, Cummings G, Hagen NA. Clinical trials focusing on cancer pain educational interventions: core components to include during planning and reporting. J Pain Symptom Manage. 2010:40(2):301-8.

89. Liaw SY, Zhou WT, Lau TC, Siau C. Chan SW-c. an interprofessional communication training using simulation to enhance safe care for a deteriorating patient. Nurse Educ Today. 2014;34(2):259-64

90. Hammick M, Freeth D, Koppel I, Reeves S, Barr H. A best evidence systematic review of interprofessional education: BEME guide no. 9. Med Teach. 2007;29(8):735-51.

91. Freeth $D$, Reeves $S$. Learning to work together: using the presage, process, product (3P) model to highlight decisions and possibilities. J Interprof Care. 2004;18(1):43-56

92. Narang A, Velagapudi P, Rajagopalan B, LeBude B, Kithcart AP, Snipelisky D, et al. A new educational framework to improve lifelong learning for cardiologists. J Am Coll Cardiol. 2018;71(4):454-62.

93. Caron JG, Bloom GA, Falcao WR, Sweet SN. An examination of concussion education programmes: a scoping review methodology. Inj Prev. 2015;21(5): 301-8.

94. Beech B, Leather P. Workplace violence in the health care sector: a review of staff training and integration of training evaluation models. Aggress Violent Behav. 2006;11(1):27-43.

95. Yardley S, Dornan T. Kirkpatrick's levels and education 'evidence'. Med Educ. 2012:46(1):97-106.

96. Borate N, Gopalkrishna D, Shiva Prasad H, Borate S. A case study approach for evaluation of employee training effectiveness and development program. Int J Bus Manage. 2014;2(6).

97. Goldsmith MR, Bankhead CR, Austoker J. Synthesising quantitative and qualitative research in evidence-based patient information. J Epidemiol Community Health. 2007;61(3):262-70.

98. Pham MT, Rajic A, Greig JD, Sargeant JM, Papadopoulos A, McEwen SA. A scoping review of scoping reviews: advancing the approach and enhancing the consistency. Res Synth Methods. 2014;5(4):371-85.

\section{Publisher's Note}

Springer Nature remains neutral with regard to jurisdictional claims in published maps and institutional affiliations.

Ready to submit your research? Choose BMC and benefit from:

- fast, convenient online submission

- thorough peer review by experienced researchers in your field

- rapid publication on acceptance

- support for research data, including large and complex data types

- gold Open Access which fosters wider collaboration and increased citations

- maximum visibility for your research: over $100 \mathrm{M}$ website views per year

At $\mathrm{BMC}$, research is always in progress.

Learn more biomedcentral.com/submissions 